\title{
Retalho miocutâneo bipediculado para correção do ectrópio cicatricial
}

\author{
Bipedicle myocutaneous flap for cicatricial ectropion correction
}

\author{
Lucia Miriam Dumont Lucci ${ }^{1}$ \\ Antonio Carlos Baldin² \\ Nilson Lopes da Fonseca $\mathrm{Jr}^{3}{ }^{3}$ \\ José Ricardo Carvalho Lima Rehder ${ }^{4}$
}

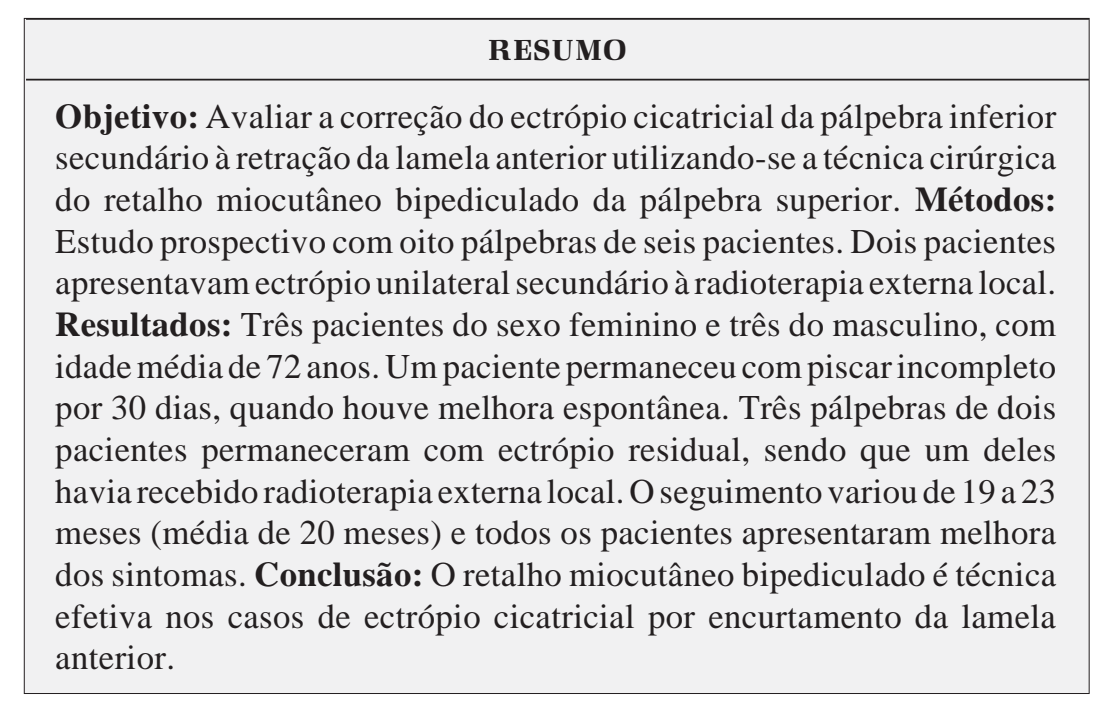

Descritores: Pálpebras/cirurgia; Ectrópio/cirurgia; Cicatriz/complicações; Retalhos cirúrgicos/métodos

\section{INTRODUÇÃO}

Ectrópio é a eversão da margem palpebral, podendo ocorrer na pálpebra superior ou inferior. Os quatro tipos principais de ectrópio são: involucional, cicatricial, congênito e paralítico. As complicações oculares são: exposição da conjuntiva tarsal, epífora e conjuntive crônica ${ }^{(1)}$.

A fisiopatologia do ectrópio cicatricial é a presença de uma cicatriz linear ou difusa na lamela anterior da pálpebra. As causas mais comuns são os traumas lacerantes diretos, queimaduras térmicas, exposição solar crônica e pós-blefaroplastia. A radioterapia local externa, usada nos casos de tumor cutâneo ou do seio da face, pode lesar a microcirculação e causar um ectrópio por encurtamento da lamela anterior.

O ectrópio é classificado de acordo com a intensidade em: discreto quando houver uma eversão dos cílios e do ponto lacrimal; moderado nos casos que a margem palpebral estiver afastada do globo ocular e severo quando houver exposição da conjuntiva tarsal ${ }^{(2)}$. O ectrópio crônico resulta na queratinização da conjuntiva, que contribui para a irritação ocular ${ }^{(2)}$.

O objetivo básico do tratamento do ectrópio palpebral é restabelecer a harmonia das forças verticais e horizontais que atuam na pálpebra para evitar traumatismos constantes na superfície ocular ${ }^{(1)}$. A perda visual pode ocorrer se houver falha na restauração da capacidade protetora das pálpebras ${ }^{(2)}$.

Além da proteção mecânica, as pálpebras possuem estruturas especializadas na proteção do globo ocular como os cílios e glândulas produtoras de 
muco e óleo. O piscar distribui o filme lacrimal sobre a superfície do globo ocular protegendo-o de fatores externos.

Assim sendo, a reconstrução palpebral deve agir na sua fisiopatologia de modo a corrigir anatômica e fisiologicamente, ficando a estética num segundo plano. A reconstrução da pálpebra e da região periocular deve preservar estruturas importantes e fornecer tecido de características semelhantes, pele na camada externa e mucosa na camada interna.

Dentre as várias técnicas de reconstrução da pálpebra inferior, a técnica de retalho de espessura total bipediculado foi desenvolvida para a correção de defeitos de espessura total da pálpebra inferior ${ }^{(3)}$.

Nos casos de encurtamento da lamela anterior da pálpebra inferior, com conseqüente ectrópio cicatricial, deve-se repor tecido necessário para se refazer a mesma. As áreas doadoras de pele mais comuns são as regiões: retroauricular, supraclavicular e interna do braço. É indispensável que o leito receptor tenha um bom suprimento sangüíneo para que ocorra uma completa neovascularização do enxerto. Complicações possíveis de um enxerto são: hematoma, infecção, necrose e retração após algum tempo da cirurgia.

Nos casos onde o leito receptor não apresenta condições favoráveis, deve-se utilizar a técnica do retalho para a reconstrução palpebral para se evitar a isquemia ou a necrose do tecido.

Levin e Leone, descreveram a técnica do retalho miocutâneo bipediculado da pálpebra superior para a correção do ectrópio cicatricial da pálpebra inferior em nove pálpebras ${ }^{(4)}$. Neste estudo nenhum paciente havia sido submetido à radioterapia local externa.

O objetivo deste estudo é avaliar a técnica cirúrgica e os resultados do retalho miocutâneo bipediculado proveniente da pálpebra superior para a correção do ectrópio cicatricial da pálpebra inferior.

\section{MÉTODOS}

Estudo prospectivo com pacientes atendidos no setor de Plástica Ocular da Disciplina de Oftalmologia da Faculdade de Medicina do ABC após aprovação do Comitê de Ética em Pesquisa da instituição. A amostra do estudo constitui-se de seis indivíduos portadores de ectrópio cicatricial por encurtamento da lamela anterior na pálpebra inferior. Todos os pacientes foram submetidos ao exame oftalmológico completo e foram esclarecidos em relação ao tratamento cirúrgico.

Quatro pacientes apresentavam ectrópio unilateral e dois pacientes apresentavam a alteração palpebral bilateral, totalizando oito pálpebras estudadas. Com relação à intensidade, seis pálpebras apresentavam ectrópio moderado e duas pálpebras apresentavam ectrópio severo.

Havia dois pacientes que tinham sido submetidos à radioterapia externa. Um caso para tratamento de um tumor do seio da face e estava associado a lagoftalmo. Outro caso para tratamento de tumor cutâneo na região periocular e era olho único.

\section{Técnica cirúrgica do retalho miocutâneo bipediculado}

A cirurgia iniciava com a demarcação de pele a ser incisada. A incisão na pálpebra inferior era feita dois milímetros abaixo da linha dos cílios. Na pálpebra superior eram feitas duas linhas paralelas que demarcavam o retalho bipediculado, sendo que a primeira linha coincide com a prega palpebral superior e a segunda linha era marcada com uma pinça atraumática que quantificava o excesso de pele pré-septal, estando o paciente com as pálpebras fechadas. As duas linhas da pálpebra superior não se unem nos cantos medial e lateral. A linha superior é um pouco mais extensa do que a linha inferior. A linha inferior se une nos cantos medial e lateral à linha infraciliar da pálpebra inferior (Figura 1).

A presença de dois pedículos (medial e lateral) garante o suprimento sangüíneo bilateral de tal forma que este retalho se comporta como dois retalhos monopediculados, onde a proporção 1:4 na relação largura:comprimento é suficiente para a vascularização até a extremidade do retalho. Por se tratar de um retalho bipediculado, mantivemos a relação 1:8 (largura: comprimento), onde cada pedículo é responsável pela vascularização da metade do retalho.

Anestesia local era feita com lidocaína a $2 \%$ e epinefrina 1:100.000 no plano entre a pele e o músculo orbicular. Foi passado um ponto na margem palpebral inferior com o fio de seda trançado 4-0 (Seda ${ }^{\circledR}$ - Ethicon) e tracionado superiormente, semelhante a uma sutura de Frost.

Incisão de pele era feita com lâmina $\mathrm{n}^{\circ} 15$. Na pálpebra inferior, realizava-se a dissecção do músculo orbicular prétarsal, exposição do tarso e preparo do leito receptor com cauterização mínima dos vasos sangüíneos. Na pálpebra superior, o músculo orbicular subjacente à pele era dissecado num só plano, deixando intactos os pedículos medial e lateral.

O retalho bipediculado era deslizado para o leito receptor na pálpebra inferior. A sutura da pele das pálpebras superior (área doadora) e inferior (área receptora) era realizada com o fio de seda trançado 6-0 (Seda ${ }^{\circledR}$ Ethicon). A sutura de reparo da pálpebra inferior e o curativo oclusivo foram mantidos por 48 horas.

Nos casos bilaterais, optou-se por fazer as cirurgias separadamente devido ao desconforto de se permanecer com os dois olhos ocluídos.

Os pacientes foram orientados a evitar traumatismo local e a usar medicação analgésica e antiinflamatória via oral. Após a retirada do curativo oclusivo e da sutura de reparo, os pacientes utilizaram colírio lubrificante e pomada de tobramicina e dexametasona quatro vezes ao dia por uma semana.

Os pontos de pele foram removidos no sétimo pós-operatório. Os retornos ao ambulatório foram com 1, 3, 6 e 12 meses após a cirurgia.

\section{RESULTADOS}

Foram operadas oito pálpebras de seis pacientes. Dois pacientes apresentavam ectrópio bilateral secundário à exposição solar crônica (Figura 2) e quatro pacientes apresentavam 

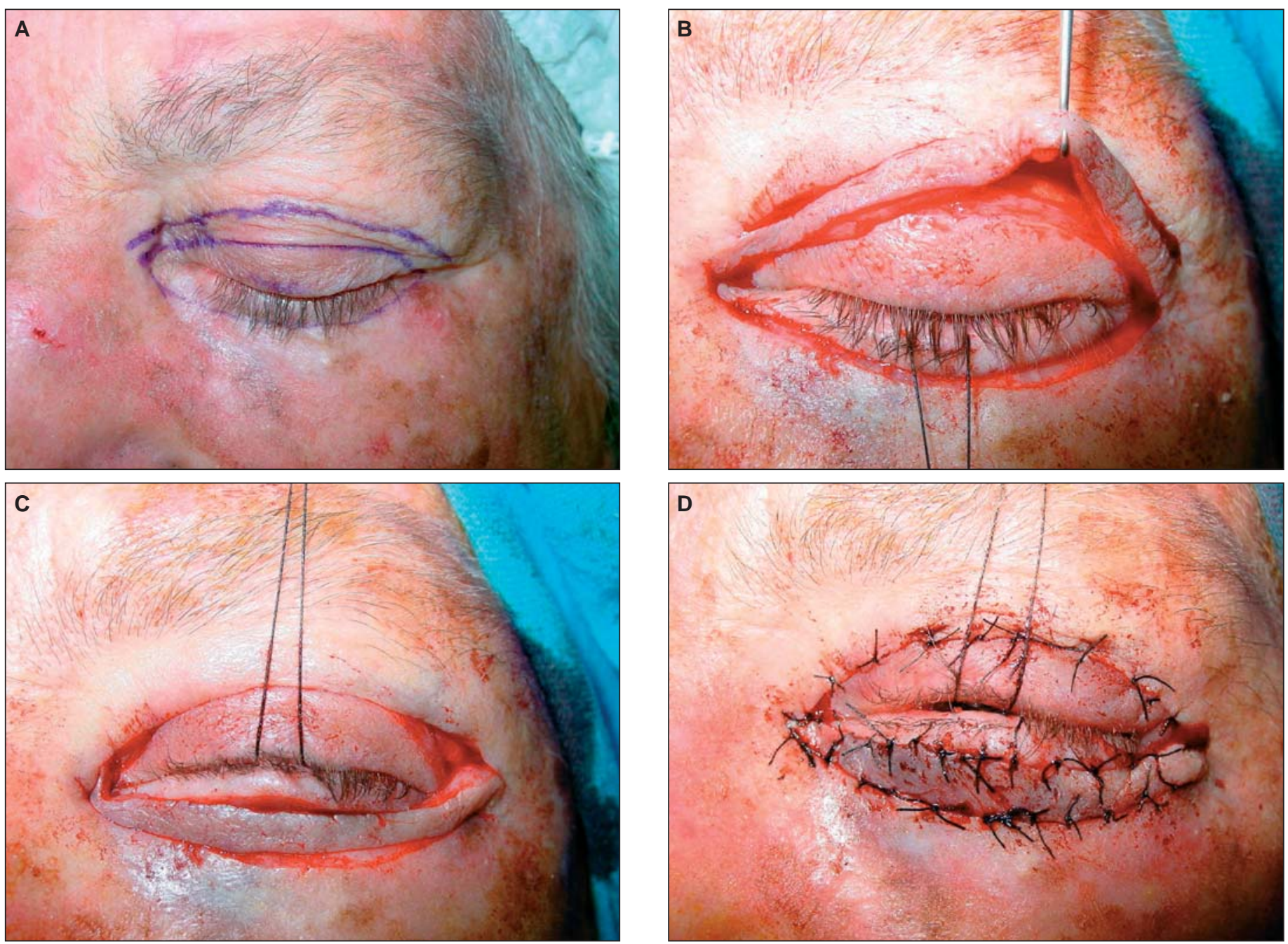

Figura 1 - Seqüência cirúrgica do retalho miocutâneo bipediculado. (A) marcação da pele na pálpebra superior e inferior; (B) incisão da pele e confecção do retalho (levantado por um gancho); (C) deslizamento do retalho da pálpebra superior para a pálpebra inferior; a sutura de reparo da pálpebra inferior está tracionada superiormente e (D) sutura da pele com pontos separados com seda 6-0

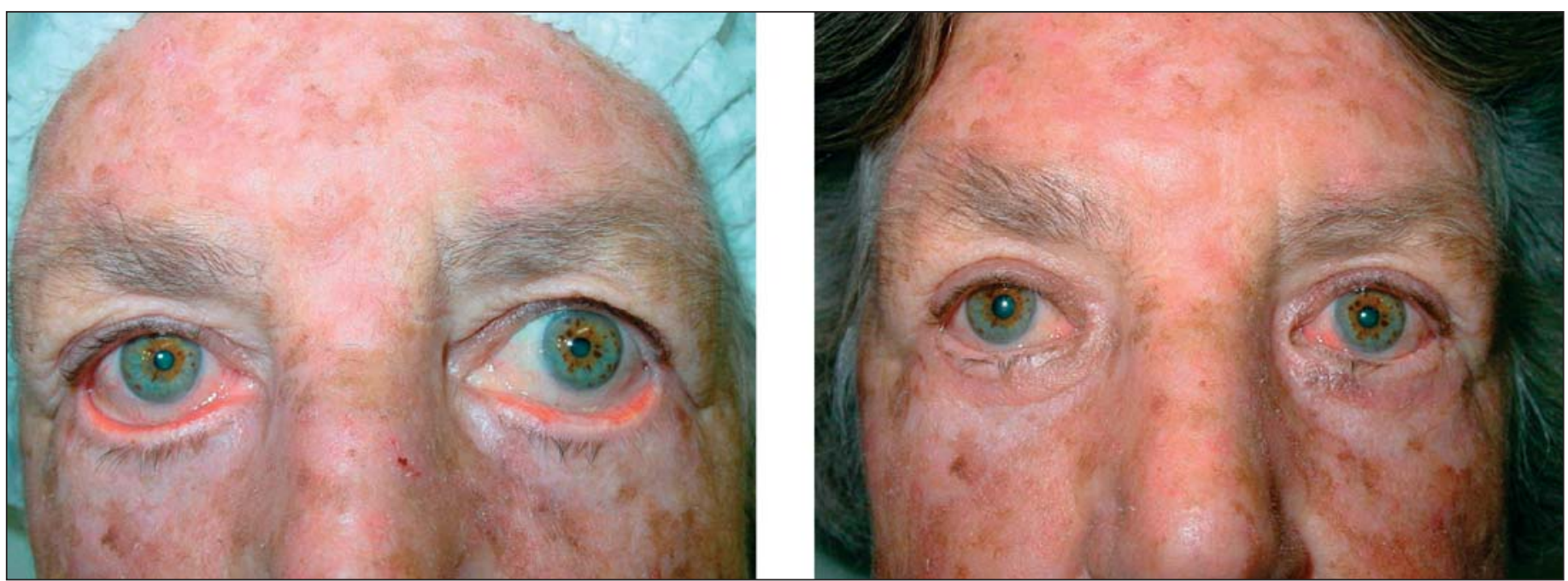

Figura 2 - Pré e pós-operatório da correção do ectrópio cicatricial nas pálpebras inferiores com a técnica do retalho miocutâneo bipediculado bilateral. Observar o fotoenvelhecimento da pele da face devido à irradiação ultravioleta crônica 
ectrópio unilateral. Dois pacientes com ectrópio unilateral haviam sido submetidos à radioterapia local externa para tratamento de tumor de seio da face (Figura 3) e tumor cutâneo na região periocular (Figura 4).

Seis pálpebras apresentavam ectrópio moderado e duas pálpebras apresentavam ectrópio severo. Com relação à lateralidade, cinco casos do olho esquerdo e três do olho direito.
Três pacientes eram do sexo masculino e três do feminino, todos da raça branca. A idade variou de 49 a 85 anos, com média de 72 anos. Nenhum paciente havia sido submetido à cirurgia prévia para correção do ectrópio palpebral.

O período de seguimento variou de 19 a 23 meses, com uma média de 20 meses. Todos os seis pacientes apresentaram melhora significativa da sintomatologia ocular. Nenhum pa-

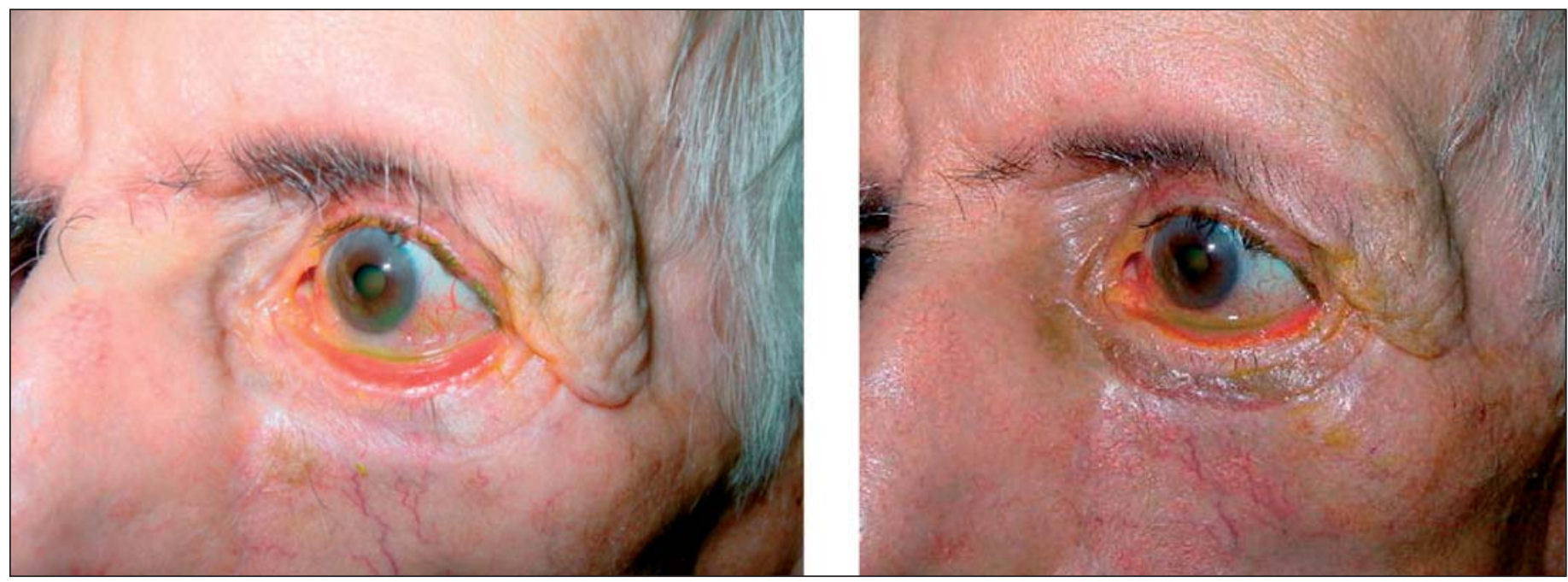

Figura 3 - Pré e pós-operatório de retalho miocutâneo bipediculado para a correção do ectrópio cicatricial da pálpebra inferior esquerda. Radioterapia externa prévia na região maxilar esquerda devido tumor no seio maxilar. Observar o afinamento da pele na pálpebra inferior esquerda e o afundamento do $1 / 3$ médio da face esquerda

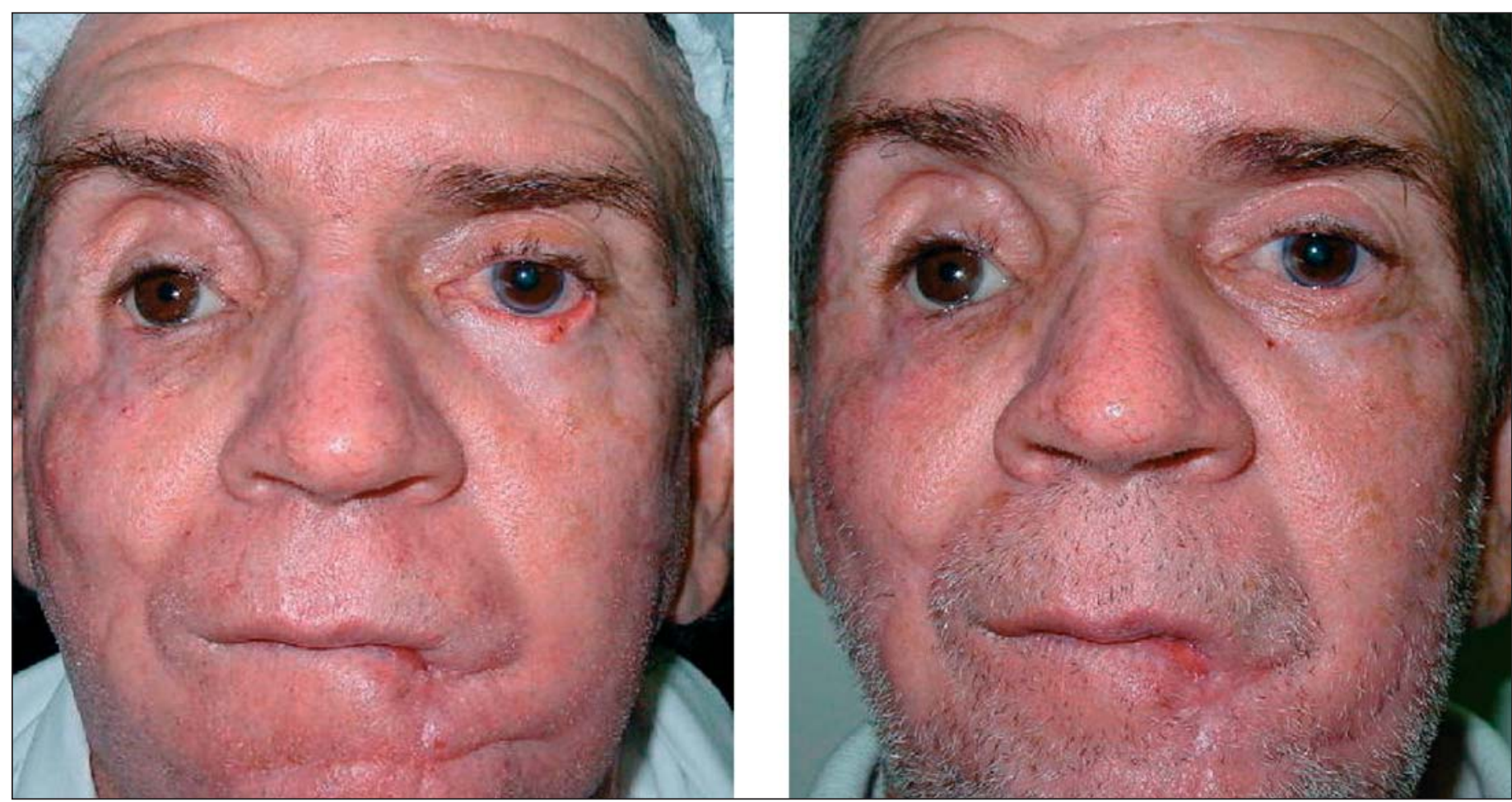

Figura 4 - Pré e pós-operatório do retalho miocutâneo bipediculado para correção do ectrópio cicatricial da pálpebra inferior esquerda. Prótese ocular à direita desde a infância e cirurgia no lábio superior para exérese de lesão tumoral. Radioterapia externa prévia para tratamento de tumor cutâneo na região periocular esquerda 
ciente apresentou alguma deformidade da margem palpebral superior ou inferior, mau posicionamento do ponto lacrimal, prega cutânea na pálpebra inferior, edema crônico, isquemia ou necrose do retalho. Durante todo o seguimento ambulatorial (média 20 meses) não se observou retração do retalho miocutâneo bipediculado e recidiva do ectrópio.

Três pacientes apresentaram complicações mínimas no pós-operatório. Um paciente com ectrópio bilateral apresentou piscar incompleto unilateral por um mês, evoluindo satisfatoriamente sem complicações oculares. Três pálpebras, de dois pacientes, apresentaram ectrópio residual moderado, sendo que um paciente apresentava uma pele actínica severa e o outro paciente havia recebido radioterapia prévia. Este último paciente permaneceu com lagoftalmo moderado.

\section{DISCUSSÃO}

A correção do ectrópio cicatricial na pálpebra inferior pode ser feita através de enxertos ou uso de tecido alogênico ${ }^{(1-7)}$. A pele ideal para a reconstrução palpebral é a localizada na região periocular, pois apresenta a mesma coloração e espessura. O enxerto pode ser feito com pele autógena ou artificial. Se a pele apresentar uma coloração ou consistência diferente, haverá um resultado estético final pouco satisfatório ${ }^{(2,7)}$.

Nos casos de enxerto de pele, as áreas doadoras preferidas são as regiões: retroauricular, supraclavicular e interna do braço $^{(2)}$. Um bom resultado cirúrgico somente pode ser obtido quando existem condições para uma completa neovascularização do enxerto, sendo indispensável que o leito receptor tenha um bom suprimento sanguíneo. A qualidade do leito receptor depende de condições locais (queimaduras e radiodermite têm pior prognóstico) e condições sistêmicas (pacientes diabéticos ou fumantes crônicos exigem maiores cuidados) ${ }^{(3,7-8)}$.

Pitanguy et al., descreveram um enxerto composto por pele e pericôndrio proveniente da superfície anterior da concha auricular para correção do ectrópio cicatricial da pálpebra inferior. Devido à atividade condrogênica, as pálpebras se tornaram firmes e apresentaram suporte local ${ }^{(6)}$.

O suporte sangüíneo de um retalho é a melhor opção nos casos onde a microcirculação está deficiente. O retalho de pele pode ser mono ou bipediculado. No retalho monopediculado é importante respeitar a proporção 1:4 na relação largura:comprimento para garantir um adequado suporte vascular até sua extremidade final ${ }^{(7)}$. O retalho bipediculado funciona com dois monopediculados, onde cada pedículo é responsável pela vascularização da metade do retalho. Na marcação de pele da pálpebra superior, deve-se tomar o cuidado para não diminuir a distância das duas linhas nas extremidades medial e lateral. As incisões devem permanecer paralelas em todo seu comprimento, do contrário o pedículo terá uma largura menor, o que irá comprometer o suporte vascular.

O pedículo de um retalho pode ou não ser incorporado ao leito receptor. Na técnica de Tripier, os pedículos medial e lateral do retalho da pálpebra superior não estão incorporados ao leito receptor. Após duas a três semanas, os pedículos são seccionados e devolvidos ao local de origem ${ }^{(9)}$. Na técnica descrita neste estudo incorporamos os pedículos ao leito receptor, não sendo necessário um segundo procedimento cirúrgico para a liberação dos mesmos.

A reconstrução topográfica de Soares utiliza um retalho miocutâneo da região pré-septal para reconstruir a lamela anterior da pálpebra inferior, semelhante à técnica descrita neste estudo $^{(9)}$.

Outros autores descreveram o retalho bipediculado de espessura total (lamela anterior e posterior) da pálpebra superior para a correção de defeitos da pálpebra inferior ${ }^{(3)}$. Nossos seis pacientes não apresentaram deficiência da lamela posterior, portanto não julgamos necessária a realização de um retalho de espessura total, mas apenas da lamela anterior.

No Brasil, assim como outros países tropicais, a exposição crônica aos raios ultravioleta leva a alteração da pele conhecida como queratose actínica. Este encurtamento da lamela anterior em toda a extensão da pálpebra inferior causa o ectrópio cicatricial que pode ser corrigido com enxertos ou retalhos.

O ectrópio cicatricial linear surge quando uma laceração atinge os planos profundos, perpendicular às fibras do músculo orbicular e os tecidos não são convenientemente aproximados na reparação primária. A indicação cirúrgica nestes casos é a zetaplastia cujos objetivos são aumentar o comprimento dos tecidos na direção desejada e mudar a posição da cicatriz de modo a situá-la na direção das linhas de força da pele ${ }^{(8)}$.

Nos casos de ectrópio da pálpebra inferior pós-blefaroplastia, muitas vezes não se tem disponível o excesso de pele na pálpebra superior, sendo necessário a realização de um levantamento do $1 / 3$ médio da face ou enxerto de pele retroauricular na pálpebra inferior.

O retalho monopediculado de espessura total para a correção de defeitos de espessura total da pálpebra inferior, normalmente após a exérese de um tumor foi descrito por Anderson et al. Trata-se de casos com lesão de espessura total e comprimento variável, onde um retalho monopediculado mantém a proporção 1:4 para a relação largura:comprimento do retalho $^{(5)}$.

Levin e Leone, utilizaram a técnica do retalho miocutâneo bipediculado em nove casos, sendo que em quatro casos haviam sido previamente submetidos à rotação de retalho da face. Nenhum desses pacientes havia recebido radioterapia prévia ou apresentavam alteração na microcirculação ${ }^{(4)}$.

O retalho composto por pele e músculo orbicular apresenta as vantagens de ter um suporte vascular satisfatório e repor os tecidos da lamela anterior na pálpebra inferior. No caso de um retalho cutâneo bipediculado para a pálpebra inferior, haveria menos suporte sangüíneo e a área receptora apresentaria um degrau entre o retalho e o tecido adjacente. A sutura nos cantos em forma de $\mathrm{V}$ deitado permite um adequado retorno venoso, minimizando o edema e a congestão.

A dificuldade da técnica cirúrgica se deve à complexidade da anatomia da região periocular, principalmente na confecção 
do pedículo medial, onde existem estruturas nobres como o tendão cantal medial, a via lacrimal excretora e a artéria angu$\operatorname{lar}^{(2-3)}$.

Esta técnica apresenta algumas limitações: necessidade de excesso de pele na pálpebra superior; assimetria da pálpebra superior nos casos unilaterais e não corrige lagoftalmo severo.

Em nenhum dos seis pacientes foi associado outra técnica cirúrgica para corrigir a flacidez horizontal. Mas, é possível, após o preparo do leito receptor, fazer uma retirada da lamela posterior em forma de pentágono para corrigir a frouxidão horizontal. Na técnica do retalho miocutâneo bipediculado é difícil a associação com a técnica do "tarsal strip" pela dificuldade da manipulação do canto lateral.

\section{CONCLUSÃO}

O retalho miocutâneo bipediculado é uma técnica efetiva no tratamento do ectrópio cicatricial da pálpebra inferior, principalmente nos casos com comprometimento da microcirculação, que poderia causar necrose no enxerto.

\section{ABSTRACT}

Purpose: To evaluate the correction of lower eyelid cicatricial ectropion due to shrinking of anterior lamela with the surgical technique of bipedicle myocutaneous flap from the upper eyelid. Methods: Prospective study with eight eyelids of six patients. There were two patients with unilateral ectropion who had received external local radiotherapy. Results: There were three male and three female patients, with mean age of 72 years. One patient presented an incomplete blinking for one month that spontaneously resolved. Three eyelids of two patients maintained a residual ectropion; one of them had received local external radiotherapy. Follow-up ranged from 19 to 23 months (mean of 20 months) and all patients improved their ocular condition. Conclusion: The bipedicle myocutaneous flap is effective for correction of cicatricial ectropion due to shrinking of anterior lamella.

Keywords: Eyelids/surgery; Ectropion/surgery; Cicatrix/complications; Surgical flaps/methods

\section{REFERÊNCIAS}

1. França VP, Bongiovanni CS, Soares EJC, Bessa H, Caldato R. Ectrópio. In: Soares EJC, Moura EM, Gonçalves JOR. Cirurgia plástica ocular. São Paulo: Roca; 1997. p.153-70.

2. Jelks GW, Jelks EB. Prevention of ectropion in reconstruction of facial defects. Clin Plast Surg. 2001;28(2):297-302.

3. Anderson RL, Weinstein GS. Full-thickness bipedicle flap for total lower eyelid reconstruction. Arch Ophthalmol. 1987;105(4)570-6.

4. Levin ML, Leone CR Jr. Bipedicle myocutaneous flap repair of cicactricial ectropion. Ophthal Plast Reconstr Surg. 1990;6(2):119-21.

5. Anderson RL, Jordan DR, Beard C. Full-thickness unipedicle flap for lower eyelid reconstruction. Arch Ophthalmol. 1988;106(1):122-5.

6. Pitanguy I, Lessa S, Sebastiá R. Tratamento dos ectrópios palpebrais com enxerto composto de pele e pericôndrio. Rev Bras Cir. 1985;75(6):429-36.

7. Vural E, Key JM. Complications, salvage, and enhancement of local flaps in facial reconstruction. Otolaryngol Clin North Am. 2001;34(4):739-51.

8. Dantas RRA, Cruz AAV, Soares EJC, Pena EP. Retrações palpebrais cicatriciais. In: Soares EJC, Moura EM, Gonçalves JOR. Cirurgia plástica ocular. São Paulo: Roca; 1997. p.65-75.

9. Mason EM, Cruz AAV, Soares EJC, Velasco EAF, Bedran EGM, Portellinha WM. Reconstrução palpebral. In: Soares EJC, Moura EM, Gonçalves JOR. Cirurgia plástica ocular. São Paulo: Roca; 1997. p.221-42.

\section{JORNADA SUL-MINEIRA DE OFTALMOLOGIA}

\section{7 e 8 de Julho de 2006 Passos - MG}

INFORMAÇÕES

E-mail: cenacon@cenacon.com.br 